\title{
Penerapan Data Envelopment Analysis dalam Pengukuran Efisiensi Retailer Produk Kendaraan Merek Toyota
}

\author{
Andrew Filardo, Nugroho Priyo Negoro, dan Aang Kunaifi. \\ Jurusan Manajemen Bisnis, Fakultas Teknologi Industri, Institut Teknologi Sepuluh Nopember (ITS) \\ Jl. Arief Rahman Hakim, Surabaya 60111 Indonesia \\ e-mail: nugroho_psu@yahoo.com
}

\begin{abstract}
Abstrak-Peningkatan penjualan mobil dari tahun ke tahun membuat semakin ketatnya persaingan bisnis sejenis pada sektor industri otomotif, sehingga dibutuhkan keefisiensian dalam menjalankan proses bisnis agar bisnis tersebut dapat terus berkompetisi di pasar. Tolak ukur efisiensi industri otomotif dalam menjalankan kegiatan bisnisnya dilihat dari seberapa besar suatu brand dapat mendominasi pangsa pasar yang ada. Akan tetapi, tolak ukur tersebut dinilai kurang efektif dikarenakan oleh capaian pangsa pasar yang diperoleh oleh suatu brand industri otomotif terlalu terfokus pada hasil akhir (output) tanpa memperhitungkan hasil usaha (input) didalam kegiatan bisnisnya. Sehingga, diperlukan suatu metode baru untuk mengukur efisiensi dari industri otomotif tersebut secara objektif. Penelitian sebelumnya juga membuktikan bahwa penggunaan market share sebagai acuan keefisiensian suatu industri otomotif dinilai kurang efektif, sehingga digunakan metode baru dalam menghitung efisiensi dari industri otomotif dengan menggunakan Data Envelopment Analysis (DEA). Penelitian ini bertujuan untuk menerapkan $D E A$ tersebut dalam pengukuran efisiensi retailer produk kendaraan merek Toyota di Jawa Timur. Metode yang digunakan adalah Data Envelopment Analysis (DEA), dengan objek amatan penelitian ini adalah seluruh outlet AUTO2000 di Jawa Timur sebagai retailer dari produk kendaraan merek Toyota. Hasil yang didapat dari penelitian ini yaitu terindentifikasinya faktor-faktor yang terlibat dalam efisiensi AUTO2000 dan terlihat perbandingan keefisiensian antar DMU AUTO2000 di seluruh Jawa Timur.
\end{abstract}

Kata Kunci-DEA, Efficiency, Toyota Retailer.

\section{PENDAHULUAN}

$\mathrm{I}_{\mathrm{p}}^{\mathrm{N}}$ NDUSTRI otomotif mobil merupakan salah satu pilar penting sektor manufaktur Indonesia. Selain menopang pertumbuhan ekonomi, industri otomotif mobil juga menyediakan lapangan kerja yang besar dan menjadi sektor yang diminati para investor mancanegara [5]. Sebagai salah satu negara di ASEAN dengan populasi terbesar, Indonesia menjadi potensi pasar yang besar bagi pelaku industri otomotif. Hal ini didukung dari penelitian yang telah dilakukan oleh Direktur Riset Regional Asia-Pasifik Automotive and Transportation Practice Frost \& Sullivan, Vijay Rao, yang menyatakan bahwa Indonesia merupakan salah satu negara dengan perkembangan otomotif terbesar di ASEAN setelah Thailand. Frost \& Sullivan memprediksi Indonesia akan menjadi pasar otomotif terbesar di ASEAN pada 2019 dengan total kendaraan mencapai 2,3 juta [10]

Penelitian lain dari Sekretaris Umum Gabungan Industri Kendaraan Bermotor Indonesia (GAIKINDO), juga menyatakan hasil dari penelitiannya bahwa penjualan mobil di Indonesia hanya berbeda sekitar 100 ribu unit atau 7,5\% dari Thailand dan pertumbuhan penjualan domestik Indonesia dinyatakan dapat mencapai $23,6 \%$ per tahun di Seminar Prospek Industri Otomotif Nasional Menghadapi ASEAN Economic Community (AEC) 2015[1].

Melihat tingginya pertumbuhan industri kendaraan otomotif tersebut, maka kebutuhan akan efisiensi merupakan salah satu isu utama bagi kelangsungan hidup perusahaan dalam menghadapi persaingan [1] dan menjadi indikator penting dalam mengukur kinerja keseluruhan dari aktivitas suatu perusahaan agar perusahaan tetap kompetitif di pasar [13]. Evaluasi efisiensi mampu mengidentifikasi tolok ukur dalam kelompok organisasi bisnis serupa yang menawarkan informasi yang berguna untuk pengambilan keputusan. Patokan tersebut biasanya mewakili rata-rata kinerja, dan dengan demikian memberikan dealer dengan kesempatan untuk mengidentifikasi area perbaikan dengan membandingkan kinerja mereka relatif terhadap perusahaan sejenis [7].

Pada industri otomotif, efisiensi dealer merupakan faktor utama dalam memperoleh dan mempertahankan daya saing. Oleh karena itu, sangat penting untuk membangun model guna menilai efisiensi jaringan distribusi yang mungkin berguna tidak hanya untuk dealer, tetapi juga untuk perusahaan induk

Persaingan antar industri otomotif mobil di Indonesia didominasi oleh sembilan merek bisa dilihat pada tabel 1 berikut ini.

Tabel 1 .

Persaingan antar merek mobil dalam industri mobil di Indonesia.

\begin{tabular}{lrrrrrr}
\multicolumn{1}{c}{ MEREK } & 2010 & 2011 & 2012 & \multicolumn{1}{c}{2013} & \multicolumn{1}{c}{2014} & \multicolumn{1}{c}{2015} \\
\hline TOYOTA & $36,8 \%$ & $34,8 \%$ & $36,3 \%$ & $40.56 \%$ & $41.8 \%$ & $31.8 \%$ \\
DAIHATSU & $11,5 \%$ & $15,6 \%$ & $15,9 \%$ & $14.82 \%$ & $14.01 \%$ & $16.5 \%$ \\
MITSUBISHI & $13,9 \%$ & $15,0 \%$ & $13,3 \%$ & $10.71 \%$ & $9.11 \%$ & $11.1 \%$ \\
SUZUKI & $9,3 \%$ & $10,6 \%$ & $11,3 \%$ & $14.76 \%$ & $13.23 \%$ & $12 \%$ \\
HONDA & $8,0 \%$ & $5,10 \%$ & $6,20 \%$ & $6.77 \%$ & $12.27 \%$ & $15.7 \%$ \\
NISSAN & $4,9 \%$ & $6,30 \%$ & $8,40 \%$ & $4.96 \%$ & $2.20 \%$ & $2.5 \%$ \\
ISUZU & $3,2 \%$ & $3,20 \%$ & $5,12 \%$ & $2.42 \%$ & $2.14 \%$ & $1.9 \%$ \\
HINO & $0,5 \%$ & $0,4 \%$ & $0,6 \%$ & $2.85 \%$ & $2.5 \%$ & $0.1 \%$ \\
HYUNDAI & $0,6 \%$ & $0,7 \%$ & $0,8 \%$ & $0.1 \%$ & $0.04 \%$ & $0.1 \%$ \\
LAINNYA & $7,9 \%$ & $8,7 \%$ & $8,9 \%$ & $2.05 \%$ & $2.7 \%$ & $8.3 \%$ \\
\hline \hline
\end{tabular}


Induk perusahaan otomotif menilai performa dealer mereka berdasarkan dari tingkat pangsa pasar dan merencanakan sistem insentif dengan menetapkan target penjualan tahunan untuk setiap dealer. Akan tetapi, penilaian kinerja berdasarkan perbandingan pangsa pasar antar dealer dapat menyebabkan perkiraan yang tidak tepat dan mengakibatkan penetapan target penjualan tahunan menjadi salah, karena menilai performa menggunakan metode seperti ini tidak memperhitungkan ketersediaan ataupun pemanfaatan sumber daya [2].

Seperti contoh, dealer A bisa jadi lebih efisien dibandingkan dengan dealer B berdasarkan metode market share, apabila dealer A mendapatkan nilai output yang lebih, misalnya penjualan yang lebih tinggi, dibandingkan dengan dealer $\mathrm{B}$. Tetapi ternyata, hal tersebut dicapai dikarenakan oleh dealer A menggunakan nilai input yang lebih, seperti misalnya memulai kegiatan bisnisnya lebih dahulu di bandingkan $\mathrm{B}$, sehingga dealer A memiliki daerah cakupan pasar yang lebih banyak dibandingkan, dan memiliki posisi yang lebih strategis dibandingkan dengan dealer B. Atau bisa disimpulkan bahwa, apabila sebuah dealer memiliki tingkat input yang sama dibandingkan dengan dealer lainnya, tetapi menggunakan tingkat output yang lebih tinggi, maka dapat dikatakan bahwa dealer tersebut sebagai efisien, dan begitu pula sebaliknya [12].

Dasar dari efisiensi adalah rasio perbandingan output terhadap input [9], sehingga diperlukan suatu metode untuk dapat mengevaluasi efisiensi perusahaan secara objektif berdasarkan pengeluaran input yang dilakukan untuk mendapatkan suatu hasil output. Menanggapi konsep tersebut, Data Envelopment Analysis (DEA) sudah diakui sebagai alat yang dapat merepresentasi pengevaluasian kinerja dengan menggunakan teknik berbasis program linier untuk mengukur efisiensi unit organisasi yang dinamakan Decision Making Units (DMU). DMU adalah entitas-entitas yang akan diukur efisiensinya secara relatif terhadap sekelompok entitas lainnya yang homogen. Homogen berarti input dan output dari DMU yang dievaluasi harus sama atau sejenis. DMU dapat berupa entitas komersial maupun publik. dimana dalam penelitian ini, DMU dalam penelitian ini merupakan retailer mobil merek Toyota yaitu AUTO2000 selaku dealer resmi Toyota.

Tujuan dari penelitian ini adalah untuk menerapkan Data Envelopment Analysis (DEA) dalam pengkuruan efisiensi dari dealer AUTO2000 serta memberikan implikasi manajerial dengan menetapkan target capaian kepada dealer sebagai strategi untuk melakukan perbaikan efisiensi kinerja. DEA bekerja dengan langkah mengidentifikasi unit yang akan di evaluasi, input yang dibutuhkan serta output yang dihasilkan unit tersebut. Kemudian membentuk efficiency frontier atas set data yang tersedia dan menghitung nilai efisiensi dari unit-unit yang tidak termasuk dalam efficiency frontier (tidak efisien) yang kemudian ditentukan target efisiensi agar unit tersebut lebih efisien.

\section{KAJIAN PUSTAKA}

\section{A. Konsep Efisiensi}

Efisiensi merupakan salah satu parameter kinerja yang secara teoritis mendasari seluruh kinerja sebuah organisasi [8].
Pengukuran parameter kinerja diharapkan dapat menghasikan output yang maksimal dengan input yang ada. Pada saat pengukuran efisiensi dilakukan, perusahaan dihadapkan pada kondisi bagaimana mendapatkan tingkat output yang optimal dengan tingkat input yang ada, atau menemukan tingkat input yang minimum dengan capaian tingkat output tertentu. Dengan diidentifikasikannya alokasi input dan output, dapat dianalisis lebih jauh untuk melihat penyebab ketidakefisiensian.

\section{B. Data Envelopment Analysis}

DEA adalah sebuah teknik pemrograman matematis berdasarkan pada linier programming yang digunakan untuk mengevaluasi efisiensi dari suatu unit pengambilan keputusan (unit kerja) yang bertanggung jawab menggunakan sejumlah input untuk memperoleh suatu output yang ditargetkan. Metode DEA diciptakan sebagai alat evaluasi kinerja suatu aktivitas di sebuah unit entitas (organisasi) yang selanjutnya disebut Decision Making Unit (DMU). Secara sederhana, pengukuran ini dinyatakan dengan rasio: output/input, yang merupakan suatu pengukuran efisiensi atau produktivitas

Dalam pengukuran efisiensi dengan menggunakan DEA terdapat dua model yang sering digunakan, yaitu Constant Return to Scale (CRS) dan Variable Return to Scale (VRS). Namun, pada penelitian ini menggunakan CRS. Model DEA ini berorientasi pada input berdasarkan asumsi constant return to scale sehingga dikenal dengan model CCR. Dalam model constant return to scale setiap DMU akan dibandingkan dengan seluruh DMU yang ada di sampel dengan asumsi bahwa kondisi internal dan eksternal DMU adalah sama. Kritik terhadap asumsi ini adalah bahwa asumsi constant return to scale hanya sesuai untuk kondisi dimana seluruh DMU beroperasi pada skala optimal. Namun, dalam kenyataannya meskipun DMU tersebut beroperasi dengan sumber daya (input) yang sama dan menghasilkan output yang sama pula tetapi kondisi internal dan eksternalnya mungkin berbeda sehingga dapat mengakibatkan sebuah DMU tidak beroperasi pada skala optimal. Menurut Charnes, Cooper, dan Rhodes model ini dapat menunjukkan technical efficiency secara keseluruhan atau nilai dari profit efficiency untuk setiap DMU.

Pengukuran berorientasi input menunjukkan sejumlah input dapat dikurangi secara proporsional tanpa mengubah jumlah output yang dihasilkan. Dengan menggunakan model berorientasi input, maka model tersebut akan menghitung pengurangan input yang diperlukan untuk menghasilkan kinerja yang efisien dengan output yang tetap. Fethi \& Pasiouras [6] mengungkapkan bahwa industri perbankan yang menggunakan pendekatan berorientasi input memiliki asumsi bahwa manajer bank akan memiliki pengawasan atau kontrol yang lebih tinggi atas input (seperti: beban-beban, karyawan, dan lain-lain) daripada output (seperti: kredit, pendapatan, dan lain-lain). Beberapa studi cenderung memilih pendekatan berorientasi input karena jumlahinput menjadi keputusan utama dalam pengambilan variabel, walaupun alasan ini tidak berlaku untuk semua industri [4]. 


\section{METODOLGI PENELITIAN}

Penelitian ini merupakan penelitian yang bersifat kuantitatif bertujuan untuk menerapkan Data Envelopment Analysis dalam pengukuran efisiensi retailer produk kendaraan merek Toyota. Objek penelitian ini adalah data input dan output dari perusahaan AUTO2000. Sementara subjek dari penelitian ini adalah dealer mobil Toyota AUTO2000 di Jawa Timur sebagai DMU. Dari total 101 outlet AUTO2000, ada 19 outlet yang tersebar di Jawa Timur yang dapat dilihat pada tabel 3 di bawah ini.

Tabel 2.

Outlet Toyota AUTO2000 di Jawa Timur.

\begin{tabular}{l|l}
\hline \hline \multicolumn{1}{c|}{ Kota } & \multicolumn{1}{c}{ Kota } \\
\hline $\begin{array}{l}\text { Auto2000 Surabaya Basuki } \\
\text { Rachmat }\end{array}$ & Auto2000 Malang Sukun \\
Auto2000 Surabaya Pecindilan & Auto2000 Malang Sutoyo \\
Auto2000 Surabaya Kenjeran & Auto2000 Kediri Sumarhadji \\
Auto2000 Surabaya Kertajaya & Auto2000 Kediri Hasanudin (Kediri2) \\
Auto2000 Surabaya Jemur Sari & Auto2000 Madiun Cokroaminoto \\
Auto2000 Surabaya Sungkono & Auto2000 Jember Hayam Wuruk \\
Auto2000 Surabaya Wiyung & Auto2000 Probolinggo Sudirman \\
Auto2000 Surabaya A.Yani & Auto2000 Banyuwangi S.Parman \\
Auto2000 Surabaya Waru & Auto2000 Gresik Manyar \\
Auto2000 Tuban Wahidin & \\
\hline \hline
\end{tabular}

Penggunaan data dalam penelitian ini didasarkan atas pengidentifikasian tentang penerapan data envelopment analysis dalam pengukuran efisiensi pada AUTO2000. Sehingga pada penelitian ini dapat ditentukan data yang akan diolah terdiri dari dua jenis. yaitu input dan output. Sebagai input pada penelitian ini (X) dan output pada penelitian ini (Y) adalah komponen dari dimensi data envelopment analysis. Penentuan input dan output diambil dari Journal of Retailing volume 71 tahun 1998. Akan tetapi, berdasarkan diskusi dengan pihak expert dari perusahaan, penggunaan input dan output untuk perhitungan efisiensi dalam penelitian ini terbatas hanya menggunakan input berupa kapasitas servis dan jumlah karyawan. Sementara penggunaan output nya berupa volume penjualan dan kualitas pelayanan.

Metode analisis yang digunakan dalam penelitian ini adalah frontier non-parametrik deterministic dengan DEA. Penelitian ini bertujuan untuk menganalisis data tahunan pada sampel penelitian ini, dimana ketersediaan data yang sangat terbatas untuk memenuhi penggunaan pendekatan lain, serta penggunaan multi input dan multi output yang sukar di akomodir oleh pendekatan lainnya. Dalam DEA, efisiensi relatif DMU didefinisikan sebagai rasio dari total output tertimbang dibagi total input tertimbangya (total weighted output/total weighted input). Inti dari DEA adalah menentukan bobot (weights) atau timbangan untuk setiap input dan output DMU.

Bobot tersebut memiliki sifat : (1) tidak bernilai negatif, dan (2) bersifat universal, artinya setiap DMU dalam sampel harus dapat menggunakan seperangkat bobot yang sama untuk mengevaluasi rasionya (total weighted output/total weighted input) dan rasio tersebut tidak boleh lebih dari 1 (total weighted output/total weighted input $<1$ ).
Ada beragam tipologi pendekatan DEA yang berbeda berdasarkan analisis constant return to scale ataupun analisis variable ratio to scale, serta berdasarkan analisis input oriented ataupun output oriented. Model DEA input-oriented bertujuan untuk mengurangi jumlah input pada tingkat output, sementara model output-oriented bertujuan untuk memaksimalkan tingkat output dari penggunaan input. Model lain yang dapat memaksimalkan kelebihan input dan kekurangan output secara bersamaan, diwakili oleh model Additive [3].

Penelitian ini menggunakan model DEA CCR primal inputoriented, dimana model ini bertujuan untuk mengurangi jumlah input yang digunakan agar dapat mendapatkan hasil output pada tingkat yang sama melalui metode constant return to scale (CSR). Alasan penggunaan metode ini adalah untuk melihat dampak dari perubahan nilai yang dilakukan terhadap input perusahaan untuk mendapatkan hasil output dengan nilai yang sama:

$$
\begin{aligned}
\text { Model CCR primal : } & \max h_{k}=\sum_{r=1}^{s} U_{r} Y_{r k} \\
\text { Subject to : } & \sum_{i=1}^{y_{i}} V_{i} X_{i k}=1 \\
& \sum U_{r} Y_{r j}-\sum V_{\mathrm{i}} X_{i j} \leq 0 \\
& U_{r}, V_{i} \geq \varepsilon
\end{aligned}
$$

Dimana:

$$
\begin{aligned}
& \mathrm{U}_{\mathrm{r}}=\text { bobot yang di tentukan terhadap output } \mathrm{r} \\
& \mathrm{s}=\text { jumlah output } \\
& \mathrm{Vr}=\text { bobot yang ditentukan terhadap input i } \\
& \mathrm{m}=\text { jumlah input } \\
& \mathrm{h}_{\mathrm{k}}=\text { efisiensi relatif terhadap DMU ke } \mathrm{k} \\
& n=\text { jumlah } D M U \\
& \varepsilon=\text { konstanta positif bobot DMU }
\end{aligned}
$$

\section{ANALISIS DAN DISKUSI}

Pengolahan data input dan output dilakukan oleh peneliti dengan memberikan bobot terhadap input dan output tersebut menggunakan instrumen berupa add-in solver pada software microsoft excel yang menggunakan model DEA CCR primal dengan memaksimalkan fungsi objektif berbasis input-oriented. Tahap pengolahan data input untuk setiap DMU AUTO2000 Jawa Timur dimulai dengan memberikan pembobotan untuk setiap input dan output per tahunnya, mulai pada tahun 2014, 2015, dan 2016. Nilai pembobotan tersebut merupakan besarnya kontribusi terhadap keefisiensian DMU. Nilai bobot tersebut kemudian dikali dengan nilai data input per DMU yang selanjutnya diproses lagi dengan menggunakan formula DEA CCR primal agar didapatkan nilai skala efisiensinya.

Hasil pengolahan skala efisiensi menunjukan tingkat keefisiensian relatif dari setiap DMU AUTO2000 di Jawa Timur. Skala efisiensi didapatkan melalui hasil formulasi model DEA CCR primal antara tiap input dan output DMU. Apabila DMU mendapatkan nilai efisiensi kurang dari $100 \%$, maka DMU tersebut dikatakan relatif tidak efisien. Sementara apabila nilai efisiensi tersebut sama dengan $100 \%$, maka DMU tersebut dikatakan relatif efisien. 


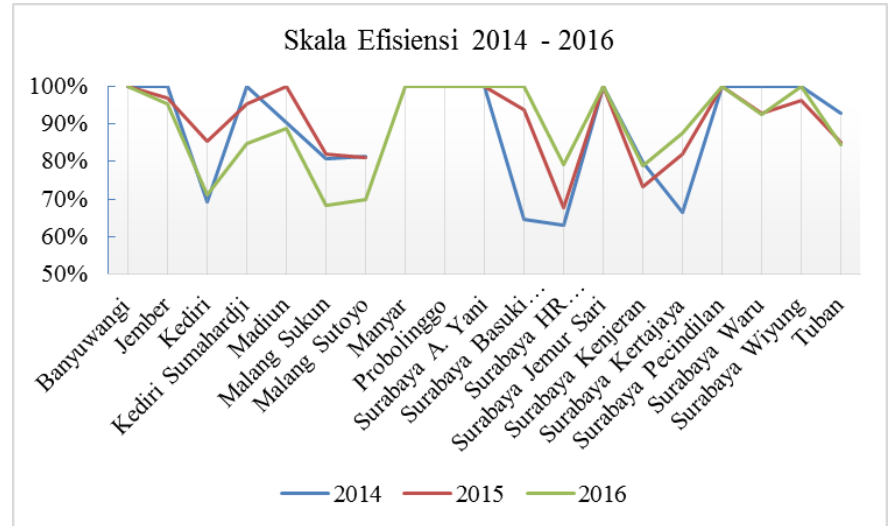

Gambar. 1. Skala Efisiensi DMU AUTO2000 di Jawa Timur 2014-2016.

Setelah mendapatkan perbandingan skala efisiensi dan besar kecilnya pengaruh kontribusi dari input terhadap efisiensi, selanjutnya akan diberikan analisis perbaikan terhadap setiap DMU per tahun agar didapatkan DMU dengan skala efisiensi yang efisien. Perbaikan efisiensi terhadap DMU yang relatif tidak efisien pada tahun 2014, 2015 dan 2016 dapat dilihat pada tabel dibawah ini.

Tabel 3.

\begin{tabular}{|c|c|c|c|c|c|c|c|c|c|c|}
\hline \multirow[b]{4}{*}{ No } & \multirow[b]{4}{*}{ DMU } & & & & & & & & & \\
\hline & & \multirow{2}{*}{\multicolumn{3}{|c|}{$\begin{array}{c}\text { Sebelum } \\
\text { Input }\end{array}$}} & \multirow{2}{*}{\multicolumn{3}{|c|}{$\begin{array}{c}\text { Sesudah } \\
\text { Input }\end{array}$}} & \multirow{2}{*}{\multicolumn{3}{|c|}{$\begin{array}{c}\text { Perubahan } \\
\text { Input }\end{array}$}} \\
\hline & & & & & & & & & & \\
\hline & & $\begin{array}{c}\text { Karyaw } \\
\text { an } \\
\text { Sales }\end{array}$ & $\begin{array}{c}\text { Karyaw } \\
\text { an } \\
\text { Servis }\end{array}$ & $\begin{array}{c}\text { Kapasit } \\
\text { as } \\
\text { Servis }\end{array}$ & $\begin{array}{c}\text { Karyaw } \\
\text { an } \\
\text { Sales }\end{array}$ & $\begin{array}{c}\text { Karya } \\
\text { wan } \\
\text { Servis }\end{array}$ & $\begin{array}{c}\text { Kapasit } \\
\text { as } \\
\text { Servis }\end{array}$ & $\begin{array}{c}\text { Karyaw } \\
\text { an } \\
\text { Sales }\end{array}$ & $\begin{array}{c}\text { Karyaw } \\
\text { an } \\
\text { Servis }\end{array}$ & $\begin{array}{c}\text { Kapasit } \\
\text { as } \\
\text { Servis }\end{array}$ \\
\hline 1 & Surabaya HR Muhammad & 40 & 41 & 19 & 25 & 26 & 12 & -15 & -15 & -7 \\
\hline 2 & Surabaya Basuki Rahmat & 51 & 37 & 21 & 33 & 27 & 14 & -18 & -10 & -7 \\
\hline 3 & Surabaya Kertajaya & 34 & 42 & 20 & 23 & 28 & 13 & -11 & -14 & -7 \\
\hline 4 & Surabaya Kenjeran & 24 & 31 & 18 & 23 & 26 & 15 & -1 & -5 & -3 \\
\hline 5 & Tuban & 28 & 19 & 14 & 28 & 20 & 13 & 0 & 1 & -1 \\
\hline 6 & Malang Sutoyo & 51 & 30 & 11 & 45 & 30 & 9 & -6 & 0 & -2 \\
\hline 7 & Kediri & 52 & 40 & 15 & 39 & 30 & 10 & -13 & -10 & -5 \\
\hline 8 & Madiun & 33 & 24 & 10 & 31 & 28 & 10 & -2 & 4 & 0 \\
\hline 9 & \begin{tabular}{|l} 
Malang Sukun \\
\end{tabular} & 42 & 24 & 17 & 39 & 21 & 14 & -3 & $\frac{-7}{-3}$ & -3 \\
\hline
\end{tabular}

Tabel 4.

DMU yang relatif tidak efisien pada tahun 2015

\begin{tabular}{|c|c|c|c|c|c|c|c|c|c|c|}
\hline \multirow[b]{3}{*}{ No } & \multirow[b]{3}{*}{ DMU } & \multirow{2}{*}{\multicolumn{3}{|c|}{$\begin{array}{c}\text { Sebelum } \\
\text { Input }\end{array}$}} & \multirow{2}{*}{\multicolumn{3}{|c|}{$\begin{array}{c}\text { Sesudah } \\
\text { Input }\end{array}$}} & \multirow{2}{*}{\multicolumn{3}{|c|}{$\begin{array}{c}\text { Perubahan } \\
\text { Input }\end{array}$}} \\
\hline & & & & & & & & & & \\
\hline & & $\begin{array}{c}\text { Karyaw } \\
\text { an } \\
\text { Sales }\end{array}$ & $\begin{array}{c}\text { Karya } \\
\text { wan } \\
\text { Servis }\end{array}$ & $\begin{array}{c}\text { Kapasit } \\
\text { as } \\
\text { Servis }\end{array}$ & $\begin{array}{c}\text { Karyaw } \\
\text { an } \\
\text { Sales }\end{array}$ & $\begin{array}{c}\text { Karya } \\
\text { wan } \\
\text { Servis }\end{array}$ & $\begin{array}{c}\text { Kapasita } \\
\text { s Servis }\end{array}$ & $\begin{array}{c}\text { Karya } \\
\text { wan } \\
\text { Sales }\end{array}$ & $\begin{array}{c}\text { Karyaw } \\
\text { an } \\
\text { Servis }\end{array}$ & $\begin{array}{c}\text { Kapasit } \\
\text { as } \\
\text { Servis }\end{array}$ \\
\hline 1 & Surabaya HR Muhammad & 42 & 45 & 19 & 28 & 31 & 13 & -14 & -14 & -6 \\
\hline 2 & Surabaya Basuki Rahmat & 55 & 42 & 21 & 52 & 39 & 20 & -3 & -3 & -1 \\
\hline 3 & Surabaya Waru & 34 & 20 & 14 & 32 & 19 & 13 & -2 & -1 & -1 \\
\hline 4 & Surabaya Kertajaya & 35 & 44 & 20 & 29 & 36 & 16 & -6 & -8 & 4 \\
\hline 5 & Surabaya Kenjeran & 28 & 32 & 18 & 23 & 26 & 15 & -5 & -6 & -3 \\
\hline 6 & Tuban & 30 & 21 & 14 & 26 & 18 & 12 & 4 & -3 & -2 \\
\hline 7 & Surabaya Wiyung & 23 & 16 & 16 & 22 & 15 & 15 & -1 & -1 & -1 \\
\hline 8 & \begin{tabular}{|l} 
Malang Sutoyo \\
\end{tabular} & 55 & 37 & 11 & 45 & 30 & 9 & -10 & -7 & -2 \\
\hline 9 & Kediri & 57 & 43 & 15 & 49 & 37 & 13 & -8 & -6 & -2 \\
\hline 10 & Jember & 25 & 23 & 13 & 24 & 22 & 13 & -1 & -1 & 0 \\
\hline 11 & Malang Sukun & 48 & 26 & 17 & 39 & 21 & 14 & -9 & -5 & -3 \\
\hline 12 & Kediri 2 & 28 & 19 & 11 & 27 & 18 & 10 & -1 & -1 & -1 \\
\hline
\end{tabular}

Tabel 5.

DMU yang relatif tidak efisien pada tahun 2016

\begin{tabular}{|c|c|c|c|c|c|c|c|c|c|c|}
\hline \multirow{3}{*}{ NO } & \multirow{3}{*}{ DMU } & \multirow{2}{*}{\multicolumn{3}{|c|}{ Sebelum }} & \multirow{2}{*}{\multicolumn{3}{|c|}{$\begin{array}{c}\text { Sesudah } \\
\text { Input }\end{array}$}} & \multicolumn{3}{|c|}{ Perubahan } \\
\hline & & & & & & & & \multicolumn{3}{|c|}{ Input } \\
\hline & & $\begin{array}{c}\text { Karya } \\
\text { wan }\end{array}$ & \begin{tabular}{|c|} 
Karya \\
wan
\end{tabular} & $\begin{array}{c}\text { Kapasit } \\
\text { as }\end{array}$ & $\begin{array}{c}\text { Karya } \\
\text { wan }\end{array}$ & $\begin{array}{c}\text { Karya } \\
\text { wan }\end{array}$ & $\begin{array}{c}\text { Kapasi } \\
\text { tas }\end{array}$ & $\begin{array}{c}\text { Karya } \\
\text { wan }\end{array}$ & $\begin{array}{c}\text { Karya } \\
\text { wan }\end{array}$ & $\begin{array}{c}\text { Kapasi } \\
\text { tas }\end{array}$ \\
\hline 1 & Surabaya HR Muhammad & 47 & 49 & 19 & 37 & 39 & 15 & -10 & -10 & -4 \\
\hline 2 & Surabaya Waru & 37 & 22 & 14 & 34 & 21 & 13 & -3 & -1 & -1 \\
\hline 3 & Surabaya Kertajaya & 39 & 47 & 20 & 34 & 21 & 12 & -5 & -26 & -8 \\
\hline 4 & Surabaya Kenjeran & 31 & 38 & 18 & 26 & 32 & 15 & -5 & -6 & -3 \\
\hline 5 & Tuban & 34 & 24 & 14 & 29 & 20 & 12 & -5 & -4 & -2 \\
\hline 6 & Malang Sutoyo & 60 & 42 & 11 & 42 & 29 & 8 & -18 & -13 & -3 \\
\hline 7 & Kediri & 62 & 46 & 15 & 44 & 33 & 11 & -18 & -13 & -4 \\
\hline 8 & Madiun & 37 & 27 & 10 & 32 & 28 & 10 & -5 & 1 & 0 \\
\hline 9 & Jember & 29 & 28 & 13 & 27 & 26 & 12 & -2 & -2 & -1 \\
\hline 10 & Malang Sukun & 53 & 31 & 17 & 37 & 22 & 12 & -16 & -9 & -5 \\
\hline 11 & Kediri 2 & 33 & 22 & 11 & 29 & 19 & 10 & -4 & -3 & -1 \\
\hline
\end{tabular}

\section{SIMPULAN DAN SARAN}

\section{A. Simpulan}

Hasil dari analisis penelitian ini menghasilkan beberapa kesimpulan yang dapat ditarik dalam penelitian ini sebagai berikut:

1. Faktor input karyawan sales, karyawan servis, dan kapasitas servis memiliki kontribusi terhadap efisiensi semua DMU di Jawa Timur dengan rentang $0.1 \%$ sampai dengan $6.25 \%$.

\section{B. Saran}

Saran yang direkomendasikan dari penelitian ini ditujukan untuk perusahaan yang dijadikan sebagai objek amatan, yaitu AUTO2000 dan saran selanjutnya diperuntukan bagi penelitian selanjutnya:

1. Saran kepada DMU AUTO2000 yang relatif tidak efisien yaitu agar mempertimbangkan pembenahan penggunaan input yang berlebihan didalam proses bisnisnya agar didapatkan unit bisnis yang lebih efektif dalam melaksanakan kegiatan bisnisnya

1.Penelitian selanjutnya dapat menggunakan data dari AUTO2000 yang lebih banyak seperti misalnya menggunakan data keuangan berupa gaji karyawan, omset, pengeluaran operasional, dan lain lain.

2. Penelitian selanjutnya dapat menggunakan AUTO2000 dari wilayah ataupun provisi lain sebagai objek amatannya

3. Pada tahun 2014, terdapat 9 DMU yang dikategorikan relatif tidak efisien dengan DMU Surabaya HR Muhammad sebagai DMU yang paling relatif tidak efisien.

4. Pada tahun 2015, terdapat DMU yang dikategorikan relatif tidak efisien dengan DMU Surabaya HR Muhammad sebagai DMU yang paling relatif tidak efisien.

Pada tahun 2016, terdapat 11 DMU yang dikategorikan relatif tidak efisien dengan DMU Malang sukun sebagai DMU yang paling relatif tidak efisien

\section{DAFTAR PUSTAKA}

[1] Assaf A G, Barros C, Sellers-Rubio R. 2011. "Efficiency determinants in retail stores: a Batesian framework." Omega. 39: 283-292

[2] Biondi, Stefano., Calabrese, Armando., Capece, Guendalina., Costa, Roberta., and Di Pillo, Francesca. 2013. "A New Approach for Assessing Dealership Performance: An Application for the Automotive Industry." International Journal of Engineering Business Management.

[3] Cooper, W.W., Seiford, L.M. and Tone, K., 2006. "Introduction to data envelopment analysis and its uses: with DEA-solver software and references. " Springer Science \& Business Media.

[4] Casu, B., \& Molyneux, P. 2003. "A Comparative Study of Efficiency in European Banking." Applied Economics, 35, 1865-1876.

[5] Dewayana, Triwulandari S., Sugiarto, Dedy., \& Hetharia, Dorina. 2012. "Peluang dan Tantangan Industri Komponen Otomotif Indonesia".

[6] Fethi, M. D. \& Pasiouras, F. 2010. "Assessing bank efficiency and performance with operational research and artificial intelligence techniques: A survey." European Journal of Operational Research, 204, 189-198.

[7] Gonzalez-Padron, T., M. B. Akdeniz, and R. J. Calantone. 2014. "Benchmarking Sales Staffing Efficiency in Dealerships Using Extended Data Envelopment Analysis." Journal of Business Research 67 (9): 1904-1911.

[8] Hadad, Muliaman D., Wimboh Santoso, Dhaniel Ilyas, \& Eugenia Mardanugraha. 2003. "Analisis efisiensi industri perbankan Indonesia: Penggunaan Metode Nonparametrik Data Envelopment Analysis." Working Paper Bank Indonesia. 
[9] Keh, H. T., and S. Chu. 2003. "Retail Productivity and Scale Economies at the Firm Level: A DEA Approach." Omega 31 (2): 75-82.

[10] Kementrian Perindustrian Republik Indonesia. 2016. "Pasar Indonesia Menarik Minat Produsen Otomotif'. Media Indonesia

[11] Noegarjito. 2015. "Perkembangan Otomotif di Indonesia". Mobilkamu

[12] Yang, Fu-Chiang. 2016. "Efficiency decomposition in dealers from the perspectives of demand forecasting, sales force, and inventory control: a case study." Journal of Production Planning and Control.

[13] Yu W, Ramanathan R. 2009. "An assessment of operational efficiency of retail firms in China." Journal of Retailing and Consumer Services. 39: 109-122. 